\title{
Que direito? Trajetórias e percepções dos usuários no processo de acesso a medicamentos por mandados judiciais em Santa Catarina
}

\author{
What right? Trajectories and perceptions of users \\ in relation to the process of access to medication \\ by legal writ in Santa Catarina State
}

Silvana Nair Leite ${ }^{1}$

Ana Cristina M afra ${ }^{2}$
${ }^{1}$ Departamento de Farmácia, U niversidade de Brasília. Campus Universitário Darcy Ribeiro. 70910-900 Brasília DF.

silvana.nair@hotmail.com 2 Universidade do Vale do Itajaí.
Abstract The objective of this study was to analyze the trajectories of users from Itajaí, Santa Catarina State who receive medications by legal writ against the State of Santa Catarina, their reasons, and their views on this form of access to medications. The methodology consisted of semistructured interviews with users who requested medications in the year of 2006. Eighteen users were located and agreed to take part in the study. $\mathrm{N}$ one of the interviewees was aware that they could charge the State for the medication before being advised by their doctor (39\%), the Secretary of $\mathrm{H}$ ealth $(22 \%)$, a lawyer ( $11 \%)$, or friends or associations $(28 \%)$. The thematic analysis revealed that a major category, denominated "N ot aware of the social right" is common to all the trajectories and the way in which the users perceive the construction of the legal process. It concludes that the actual receipt of the benefit did not promote awareness of the social right, since the way in which the processes are carried out does not empower the recipients, but on the contrary, reinforces the relations of dependence and the user's perceptions of impotence.

Key words Pharmaceutical assistance, Universal access to health services, Right to health, $M$ edications
Resumo 0 objetivo do estudo foi analisar as trajetórias dos usuários de Itajaí (SC) que recebem medicamentos via mandados judiciais contra 0 Estado de Santa Catarina, suas motivações e percepções sobre esta forma de acesso aos medicamentos. A metodologia consistiu de entrevistas semiestruturadas com os solicitantes de medicamentos de Itajaí no ano de 2006. Aceitaram participar dezoito usuários. N enhum entrevistado sabia que poderia cobrar o medicamento do estado antes de ser avisado pelo médico (39\%), Secretaria de Saúde (22\%), advogado (11\%), amigos ou associações (28\%). A análisetemática revel ou que uma grande categoria, denominada " $\mathrm{Não}$ consciência do direito social", é o eixo estruturante de todas as trajetórias e forma pela qual os usuários percebem a construção do processo judicial. Conclui-se que o recebimento atual do benefício não promoveu a conscientização do direito social, pois a forma de condução dos processos não é empoderante, ao contrário, reforça as relações de dependência e a percepção de impotência do usuário. Palavras-chave Assistência farmacêutica, Acesso universal a serviços de saúde, Direito à saúde, M edicamentos 
Introdução

A garantia de assistência farmacêutica à população élei no Brasil, inserida no âmbito dos direitos sociais. A Constituição Federal, nos artigos 6o e 196, prevêo acesso universal às ações eserviços para promoção, proteção e recuperação da saúde, como direito social e dever do Estado. A Lei n 8.080/90 declara, em seu artigo 6으, que "é atribuição do Sistema Único de Saúde a execução deações de assistência terapêutica integral, inclusive farmacêutica"1. Assim, se o poder público não fornece o medicamento que os pacientes solicitam, recorrer à Justiça, para al guns autores, é o caminho esperado - seja por intermédio de defensores públicos, escritórios-modelo de universidades, advogados particulares ou, em alguns casos, do M inistério Público².

A judicialização dos direitos sociais éum tema de grande interesse atual, poistem tomado volumeeimportância econômica e de gestão dos serviços públicos nunca antes observados. Para $M$ arques ${ }^{3}$, esta questão é especialmente importante por trazer à tona a discussão sobre os limites de ação dos sistemas jurídico e político na formulação de políticas públicas e alocação de recursos. A autora chama a aten ção ainda para o fato de que este processo garante direitos individuais em detrimento deuma coletividadequenão se faz representar em juízo - a grande maioria da população, que não tem acesso à informação e nem chega ao poder judiciário.

0 número de ações judiciais contra estadose municípios para o fornecimento gratuito de medicamentos não pára de crescer. A situação atual, com milhares de mandados judiciais, consumindo milhões de reais em recursos públicos, tem causas complexas, em que os interesses legítimos - coletivos ou individuais - nem sempre vêm em primeiro lugar². Má gestão da assistência farmacêutica por municípios e estados, pressão das indústrias farmacêuticas sobre os prescritores e a população e falhas na formação dos médicos são alguns dos fatores que impulsionam o fenômeno que já está sendo considerado uma grande ameaça à sustentabilidade do SUS, atropelando outros programas e projetos na área da saúde.

Estudos sobre 0 acesso a medicamentos via judicialização no Estado do Rio de Janeiro e na cidade de São Paulo 4,5 revelaram que os gestores estão sendo obrigados a disponibilizar medicamentos que não competem ao seu nível de gestão, muitos dos quais representativos de "inovações tecnológicas" e muitas vezes sendo prescritos sem o cumprimento dos protocolos terapêu- ticos. Para estes autores, os usuários eas instituições que exercem influência sobre este processo parecem totalmente desorientados no que tange aos pleitos de acesso aos medicamentos e carentes de entendimento sobre questões relativas ao uso racional de medicamentos. M arques et al. ${ }^{6}$ levantam, ainda, a possi bilidade de tais ações acobertarem os interesses de determinados laboratórios farmacêuticos, responsáveis pela comercialização de inovações terapêuticas inacessíveis financeiramente aos autores.

No Estado de Santa Catarina, o volume das ações contra o Estado cresceviolentamentea cada ano. Dentre os usuários atual mente cadastrados na Secretaria de Estado da Saúde, 4\% são residentes nacidadedeltajaí . As informações contidas nos processos judiciais em geral são bastante limitadas, revelando apenas o nome do usuário, o medicamento pleiteado, a cidade de origem, datas e valores empenhados. Informações que possam dar pistas sobre a origem dos receituários, a forma como o usuário foi orientado, os fatores que influenciaram este processo não podem ser acessadas pelos gestores.

A compreensão dos usuários sobre esta forma de acesso aos medicamentos - suas percepções e nível de entendimento - tampouco é conhecida. A questão do direito à saúde é tema de diversos estudos, principalmenteteórico-conceituais, mas também quanto ao cumprimento do direito pelos serviços de saúde. No entanto, é o ponto de vista dos profissionais, pesquisadores egestores que prevalecenas publicações disponíveis. 0 ponto de vista dos usuários a respeito do direito à saúde ainda é pouco investigado. Ainda menos conhecida é a perspectiva do usuário em relação ao direito de acesso aos medicamentos enquanto direito à saúde.

É com esteintuito defazer emergir a perspectiva dos usuários de medicamentos de I tajaí que acessaram por mandados judiciais contra o Estado os produtos em questão que o presente estudo se propôs a reconstruir suas trajetórias, buscando compreender suas percepções sobre 0 processo de acesso a medicamentos na perspectiva da garantia do direito à saúde.

\section{M etodologia}

0 estudo foi desenvolvido com base na metodologia qualitativa de pesquisa. Foi realizado no município de I tajaí, localizado na Foz do Rio Itajaí-açú, que possui cerca de 160.000 habitantes e população predominantementeurbana. A partir 
da listagem dos processos gerados por mandados judiciais para fornecimento de medicamentos contra o Estado de Santa Catarina, foram identificados aqueles referentes a usuários residentes na cidade deltajaí ( que representam cerca de $4 \%$ do total, segundo levantamento realizado por Pereira ${ }^{7}$ em 2005) com processo ativo no período de julho de 2006. Realizou-se a busca dos mesmos via tel efone (realizaram-se até seis tentativas de contato em dias e horários alternados com cada usuário). Ao contatar os usuários, os pesquisadores explicavam sobre o estudo e convidavam-nos a participar do mesmo.

Para elucidar as trajetórias percorridas pelos usuários atéo acesso aos medicamentos via mandados judiciais contra o Estado, assim como identificar os atores sociais einstituições queinfluenciam neste caminho, foram realizadas entrevistas semiestruturadas com os usuários que aceitaram participar do estudo. As entrevistas foram realizadas no local mais apropriado para 0 usuário (em sua casa ou de familiares, associação da qual faz parte ou ainda em seu trabalho), informado pelo mesmo por telefone.

As entrevistas foram realizadas com o próprio usuário ou com seus responsáveis, seguindo o protocolo ético de pesquisa com seres humanos e solicitando a assinatura do termo de consentimento livreeesclarecido. Estas entrevistas foram gravadas e seguiam o roteiro que contemplava as seguintes questões: há quanto tempo tem o problema de saúde, há quanto tempo utiliza o medicamento, se houve outras tentativas de tratamento anteriores para o mesmo problema de saúde, por onde começou a busca pelo medicamento prescrito etodas as etapas que percorreu, quais pessoas ou instituições Ihe informaram sobre como conseguir o medicamento ou the ajudaram de alguma forma na trajetória, se já fez solicitações de medicamentos ou outros recursos nas secretarias municipal ou estadual anteriormente. Além das entrevistas, outras informações que 0 pesquisador achou pertinente (como idade, profissão, grau de escolaridade, estado civil, condição financeira) foram anotadas e incorporadas ao material das entrevistas.

A abordagem qualitativa de pesquisa, adotada para este estudo, se baseia na premissa de que os comportamentos humanos só podem ser compreendidos em seu contexto social e por isso é o ponto de vista dos sujeitos sociais que deve ser 0 objeto de estudo, procurando o significado das práticas cotidianas e sua fundamentação na cultura local e macrossocial ${ }^{8}$. Portanto, a metodologia aplicada neste projeto de pesquisa pre- tendia observar e reconhecer os valores, crenças e contingências que motivam a busca da via judicial contra o Estado para a obten ção de medicamentos e as regras sociais e institucionais que organizam esta prática.

As entrevistas, bem como as anotações durante a coleta de dados, foram transcritas e analisadas para a identificação de termos e categorias utilizando como referência os métodos deanálise e interpretação de dados propostos por $\mathrm{M} \mathrm{i-}$ nayo ${ }^{9} \mathrm{eV}$ ictora et al. ${ }^{8}$.

0 projeto de pesquisa foi avaliado e aprovado pela Comissão de Ética em Pesquisa da U NIVALI.

\section{Resultados}

A partir da listagem dos processos gerados por mandados judiciais para o fornecimento de medicamentos contra o Estado de Santa Catarina com processo ativo no período de julho de 2006, foram identificados 44 usuários residentes no município de I tajaí. Destes, onze números de telefone informados não atendiam ou eram de outras pessoas; doze não aceitaram participar da pesquisa alegando problemas de saúde, orientação do advogado ou falta de tempo; três faleceram e dezoito usuários foram localizados e aceitaram participar, moradores de diversos bairros e pertencentes às classes sociais bai xa ou média.

As trajetórias em busca dos medicamentos prescritos iniciaram, em $75 \%$ dos casos, em longas histórias de sofrimento decorrente da doença, de diferentes tratamentos e das andanças entre serviços, políticos, instituições públicas e privadas, promessas e frustrações. Em $50 \%$ dos casos, a prescrição dos medicamentos ocorreu em serviços públicos de saúde. A somatória de medicamentos solicitados por estes dezoito usuários foi de 37, sendo 31 diferentes tipos de medicamentos. Vinte e quatro prescrições utilizavam apenas a nomenclatura comercial dos medicamentos. Os diagnósticos mais comuns (referidos pelos informantes) foram artrite/artrose, doenças cardiocirculatórias e neoplasias. Estas características não diferem substancialmente dos dados relatados por outros estudos ${ }^{4,5}$. Os medicamentos mais prescritos foram leflunomide, bezafibrato, fumarato de formoterol + budesonida, lisinopril e sulfato de glicosamina + condroitina. 0 tempo entre a busca do recurso e recebimento do medicamento variou de 48 horas a 6 meses.

A trajetória dos usuários está resumida na Figura 1. 


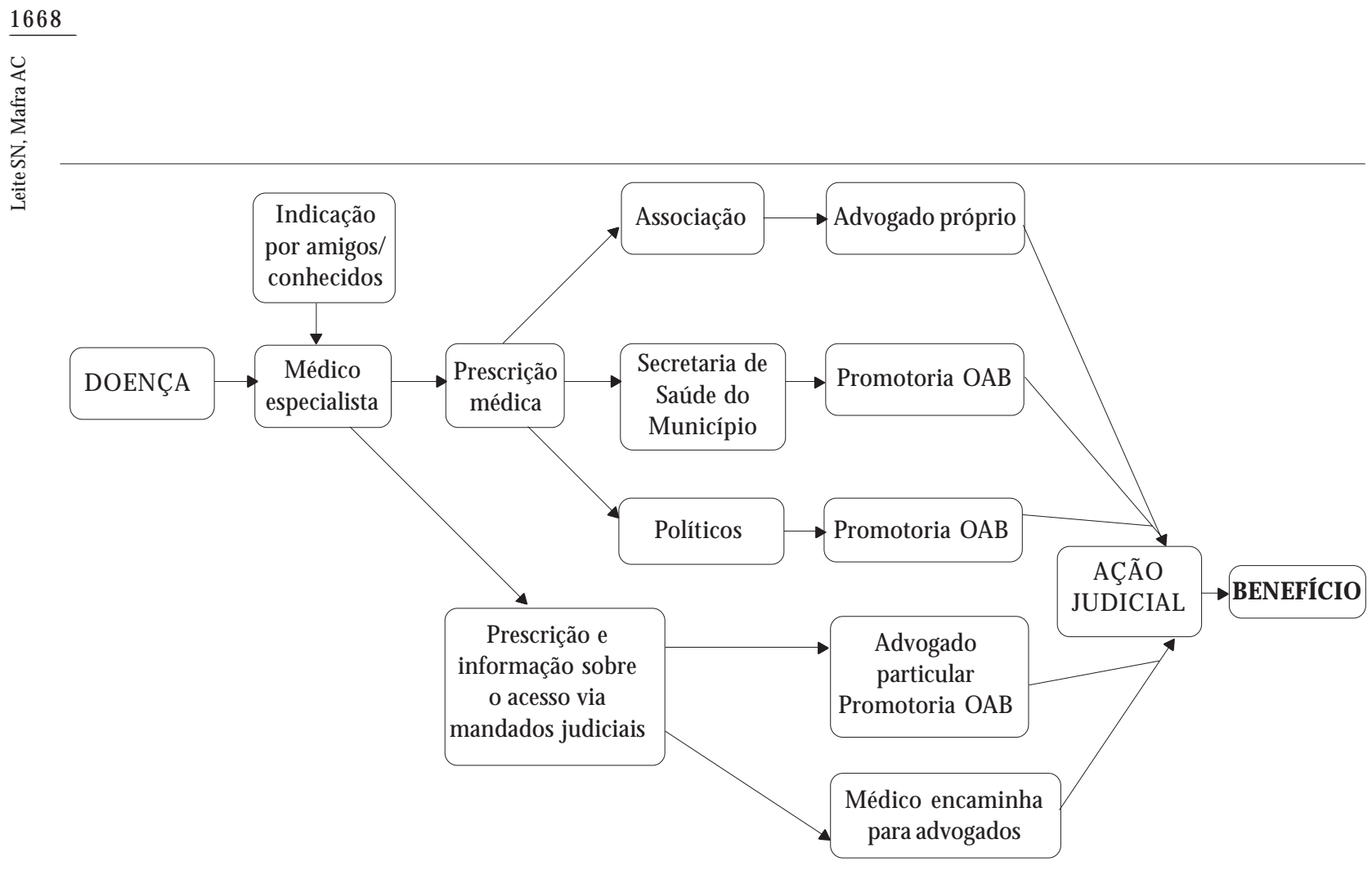

Figura 1. Trajetórias dos usuários de medicamentos de Itajaí para acesso via mandado judicial.

Nenhum entrevistado sabia que poderia cobrar o medicamento do Estado antes de ser encaminhado para esta via de acesso pelo médico (39\%), Secretaria de Saúde do município (22\%), advogado (11\%), amigos, políticos ou associações $(28 \%)$.

Os usuários com o diagnóstico da doença procuram por um médico especialista por indicação de amigos/conhecidos ou por vontade própria. 0 médico prescreve o medicamento ea busca por estemedicamento pode seguir dois caminhos:

a) ao prescrever o medicamento, o médico não informou sobre o acesso via mandados judiciais. Os usuários recebem esta informação através de políticos ou associação (da qual o usuário faz parte) ou até mesmo da Secretaria de Saúde do município e, a partir daí, os usuários procuram um advogado próprio ou promotoria ou AOB (sempre orientados para isto por um dos informantes anteriores e não por iniciativa própria), que entram com uma ação judicial contra - Estado de Santa Catarina e o usuário passa a receber o benefício;

b) ao prescrever o medicamento, o médico informou sobre 0 acesso via mandados judiciais. A partir de então, ou o usuário buscou pelo benefício com advogado particular ou promotoria ou $A O B$ (orientado pelo médico para isto), que entraram com a ação judicial contra o Estado de
Santa Catarina e então o benefício foi concedido ao usuário; ou ainda, o próprio médico, ao informar sobre 0 acesso via mandados judiciais, encaminhou o caso do paciente para advogados sem que o usuário preciseir em busca do processo, e então o advogado entrou com a ação judicial contra o Estado de Santa Catarina e o usuário passou a receber o benefício.

É importante destacar o papel dos médicos prescritores (da rede pública ou privada) e de outros profissionais da rede municipal de saúde na informação sobre a via judicial para acesso a medicamentos. Deforma geral, isto refleteo comprometimento dos profissionais para com a garantia do acesso à atenção integral e com o desenvolvimento da conscientização popular sobre 0 direito universal à saúde - comprometimento desejável e necessário. Por outro lado, é preciso questionar a prática de encaminhamento direto do médico prescritor para o sistemajurídico, através do que os usuários identificaram como "advogados próprios dos médicos", sem que o usuário necessitasse ele mesmo procurar a promotoria ou um advogado. A pesar de este estudo não ter coletado dados especificamente sobre esta questão, a preocupação de Marques e Dallari ${ }^{6}$ sobre as possíveis estratégias da indústria farmacêutica para garantir mercado consumidor, mesmo entre usuários que não têm condições finan- 
ceiras para tanto, vem à tona. Esta questão mere ce uma reflexão e investigações mais detal hadas.

M esmo quando o usuário foi encaminhado para a promotoria ou $\mathrm{OAB}$, em algumas situações, el não chegou a compreender este processo como uma defesa de seu direito de cidadão foi uma forma de poder ganhar aquele medicamento, pontualmente: $\mathrm{N}$ ão, eu fui no bem- estar pra arrumar o remédio. Aí o bem- estar me forne ceu um advogado, porque eles disseram: “N ós não temos remédio pra dar". Você vai lá no Imaruí, como é, na secretaria, assistente social, na secretaria lá, mas só quevocêtem queir na "Belia" (OAB) falar com um advogado, aí tem que entrar com um negócio de, eles sabem o que é. Aí fui ali, eles me ensinaram, fui lá num prédio redondo. Aí fui lá expliquei. Aí ela disse: "Não, nós entramos com processo, lá". (Informantel)

Apesar de o tema "judicialização do acesso à saúde" ser recorrente nas falas, nas preocupações e debates de gestores de todos os níveis, a prática do encaminhamento para o poder judiciário está disseminada nos serviços públicos, tanto na saúde quanto na assistência social. Ou seja: na ausência de formas mais adequadas de gerenciar esta questão, o próprio poder executivo está gerando sua demanda para via judicial.

A análise temática revelou que uma grande categoria, denominada aqui de "Não consciência do direito social", foi o eixo estruturante detodas as trajetórias e forma pela qual os usuários percebem a construção do processo judicial como meio de acesso aos medicamentos. Duas subcategorias foram identificadas na composição da categoria principal:

- A necessidade de justificar a solicitação do benefício najustiça: desdeo momento do contato por telefone até o transcorrer das entrevistas, os pesquisadores tiveram o cuidado de não transmitir qualquer impressão aos informantes de que fariam julgamentos a respeito de suas atitudes ou de que as entrevistas teriam finalidade regulatória. As questões do roteiro de entrevista tampouco questionavam diretamente "por que" o usuário solicitou o medicamento na justiça. M esmo assim, logo da chegada dos pesquisadores no encontro ou que iniciada a entrevista, os informantes se adiantavam em relatar suas dificuldades financeiras, o desemprego e os problemas familiares que os levaram a buscar recursos públicos: Porqueeu não posso também tá pagando $R \$ 150,00$ uma, pra mim que sou pensionista, não. N ão tenho marido, né? Os meus filhos não me ajudam, eu tenho um agora que separou, veio pra casa e aí tá comendo na minha, nas minhas costas, porque aí então eu não tenho condições, eu tenho inclusive meu IPTU está atrasado três meses, até eu tenho queir lá pra fazer uma negociação, porqueeu tinha renegociado pra pagar por mês, mas como essefinal deano deu um montede problema, eu atrasei outubro, novembro e dezembro, agora eu tô trombicada, por causa disso. (Informante E)

Eu fui obrigada a abrir o processo, né. Porque os meus remédios são muito caro e meu marido éaposentado com um salário mínimo, então a gente tem que apelar para algum lado, né. (Informante D)

A necessidade de informar que não tinham condições financeiras para comprar os medicamentos remete ao conceito que os direitos sociais são para pobres, como revela a preocupação da Informante M : Aí a assistente social veio aqui, eeu não estava, aí a conclusão dela: ela enxergou a casa, achou porque a gente tinha casa, tinha outros que tinha condições piores do que el e pra receber medicamentos. (Informante M)

Tal conceito é reforçado por alguns procedimentos rotineiros, como a avaliação socioeconômica para recebimento debenefícios da Assistência Social e declarações de profissionais: Porque atéa advogada mesmo disse: "I Isso éum direito da senhora, isso é próprio para quem não tem condições, né?" (Informante E)

Os relatos extensos sobre as dificuldades financeiras para manter o tratamento foram ouvidos de quase todos os entrevistados, sem que esta questão fosse levantada pelos pesquisadores e sempre num tom de justificativa. Além deste tema, os discursosiniciais também traziam relatos sobre a gravidade da doença, seu sofrimento físico ou psíquico decorrente e incapacidades resultantes, resultando que não tinham outra esperança quenão o tratamento em questão: $\mathrm{E}$ como eu tava muito ruim, não andava, a minha artrite já tava assim, já bem alterada, né, eu fiquei quase dois anos de cama, sem andar, sem memexer, como eu tava muito ruim, então ele tentou tratar com outras coisas, né? (Informante $S$ )

Ah, desdeunsquarenta anos, por aí assim, porque o meu marido me incomodava muito, meus nervo foram enfraquecendo, enfraquecendo, então eu não tenho mais nervos, o médico disse, qualquer coisinha eu caio até no meio da rua, se eu me incomodar. (Informante F)

M eu D eus do céu, já tô bem dizer todo "estorado", tava deitado até "inda" pouco ali no chão do "soalho". (Informante L)

Até a corrupção foi relatada por um informante como justificativa para a cobrança do medicamento do poder público: Vou tedizer uma coisa, acho que não tem nada a ver com o teu trabalho mas, porque no Brasil, eu acho assim, que dinheiro tem, me desculpe mas dizer que não tem, 
tem! Só que é mal administrado, se fosse bem administrado teria educação, saúde, é o melhor país do mundo pra se morar e nós temos de tudo de fartura, e tem, mas a roubalheira é grande, né? Então, é brabo minha filha. (Informante N).

Alguns usuários tiveram muito receio defalar sobre 0 assunto e poder perder o benefício. Dois deles só aceitaram participar por telefone; um foi primeiro consultar 0 advogado e outros se recusaram mesmo a informar sobre o processo.

- A relação de dependência e submissão ao poder público, aos médicos e aos políticos: as trajetórias revelaram as tentativas de busca pelo medicamento entreinstituições, políticos eserviços de saúde e assistência social. Os relatos das trajetórias contemplaram longas andanças, sofrimentos, peregrinações e sensação de impotência: Desses aí, ó eu fui. Eu fui no IN PS, do I N PS me mandaram pra Secretaria da Saúde, lá na, aí como que é? Eu sei que eu fui na regional, eu fui lá onde quea delegacia da mulher hoje, né? Ali na, no Dom Bosco por ali, eu fui lá no Imaruí. Não consegui nada, aí falava com a secretária, falava com um, falava com o outro funcionário da secretaria, falava com, ih meu Deus, se for contar a história toda não saio daqui hoje. $E$ durou, durou, cinco anos me enrolaram. (Informante F)

Então assim, muitas vezes não tenho dinheiro pra ir de ônibus, daí, ai, ai, eu ia, saia daqui a pé, passava o dia todo, porqueéum bom pedaço atélá no Imaruí, né? Ficava a manhã às vezes todinha, aí deixava os dois [filha e o marido doentes] com minha sogra ou com minha mãeeficava lá atéresolver. Eu saía de lá decepcionada. (Informante H).

Não são histórias pontuais, simples - foram semprecarregadas dedificuldades, deluta eesperança demelhora da sua condição de saúde. Demonstraram muito envolvimento com os problemas de saúde egrande comprometimento da vida pessoal e familiar em decorrência destes problemas.

As relações com o poder público, os médicos e os políticos revelaram a predominância da percepção pelo usuário de que um "favor" de uma pessoa foi motivadora para concessão do medicamento solicitado. 0 encaminhamento do processo diretamente por médicos prescritores (que contataram advogadose se responsabilizaram por todo o processo, sem participação ativa do usuário), a bondade de advogados que instalaram os processos sem custos para os usuários (e sem que eles saibam quem arca com este custo), a indicação específica deum funcionário de um serviço promoveram esta percepção para o usuário, como indicam as falas a seguir: Eu posso dizer que foi o doutor [médico pediatra] que conseguiu tudo pra mim, né? Assim, que eu marquei uma consulta lá com ele, fui, aí ele me explicou e aí no mesmo instante elejá mandou eu falar com o doutor. Tava ali, esqueci o nome dele. Aí eu conversei com ele e não levou um mês, não levou um mês e elejá conseguiu o remédio. Aí o doutor [médico] caiu do céu, ele pode ser ruim pra alguns, mas eu não tenho nada que reclamar. (Informante D).

Até depois ainda eu dei um presente pra ela [advogada] porque eu achei assim, que ela foi muito legal comigo, assim, né? Aí depois de eu começar a ganhar o remédio, aí eu fui lá comprei um presente e levei pra ela. (Informante $\mathrm{N}$ )

A interferência de um vereador da cidade, como no relato abaixo, também expõe esta percepção de que "alguém" precisa intervir para que se consiga acessar al gum benefício do poder público: Q uem falou mesmo foi o [vereador] que vinha aqui edisse: "A senhora usa isso tudo deremédio? A senhora compra? A senhora ganha pouco, como équea senhora sustenta a casa eainda gasta isso tudo? Não, pode deixar que eu vou arrumar um primo meu que é advogado, ele vai entrar na justiça pra senhora ganhar, vou dar uma ajuda pra senhora". (Informante S)

\section{Dependência einsegurança:} que direito à saúde é este?

Os informantes deste estudo estavam, no momento das entrevistas, recebendo medicamentos do estado, muitos deles de elevado valor financeiro, através de um mandado judicial que Ihes resguardava o direito social de acesso à saúde. Tinham, portanto, experiência materializada de quetinham direito assegurado por lei. No entanto, a conscientização de que esteera seu direito de cidadão, sem condicionantes ou possibilidade de ser questionado, não estava plenamente absorvida entreeles.

Tais relatos de justificativas, tanto de ordem financeira quanto da gravidade do problema de saúde, edemonstrações explícitas detemor quanto à manuten ção do seu benefício caso fosseidentificado como autor de processo denotaram a insegurança dos beneficiados quanto à lisura da ação empreendida: os sujeitos não queriam falar sobre isto ou, ao menos, procuraram enfatizar que real mentehavia a necessidade de buscar esta forma de acesso, de que não se tratava de "malandragem" ou má-fé.

Como configuração preestabelecida nas instituições brasileiras e na sua cultura popular como forma de obtenção do que, na verdade, "pode" (que pode "não poder" em diversas situ- 
ações) , 0 "jeitinho" inclui a utilização das relações pessoais - amizade, troca defavores, referência à "alguém" que tem a influência necessária ${ }^{10,11}$. As vias legais não pareceram eficientes aos ol hos dos usuários. Assim, para os informantes "foi o doutor [médico pediatra] que conseguiu tudo pra mim", "ela foi muito legal comigo", "foi o vereador que deu uma ajuda". A "consciência de posição social" dos informantes ${ }^{12}$ foi revelada neste sentido, poisfoi o outro, pertencentea outra classe social, que pode fazer a ponte entre o sujeito comum e os benefícios do poder público.

Desta forma, segundo Damatta ${ }^{11}$, é que 0 povo brasileiro entende a forma adequada de proceder socialmente, "uma forma ou estilo de conciliar ordens impossíveis de serem cumpridas com situações específicas, e - também - um modo ambíguo de burlar as leis e as normas sociais mais gerais". No caso estudado, no entanto, é um direito assegurado por lei e assim outorgado pela justiça que se quer alcançar, e não um "burlar" algo.

Então, por quea insegurança quanto à continuidade de recebimento do benefício? Por que supor que o processo judicial pode ser interpretado como ato de má-fé? Por que precisar invocar as relações pessoais e alguém influente para acessar um direito social?

Os relatos aqui descritos indicam que o rece bimento atual do benefício - o medicamento acessado através de um mandado judicial que afirma o direito social do cidadão e se justifica nestes termos, não éo resultado deuma conscientização deste direito pelos usuários, como supõem muitos profissionais de saúde e gestores ${ }^{2}$. Ao contrário: não está promovendo a conscientização deste direito pelos usuários, pois a forma de condução dos processos e as relações que se constroem nas trajetórias não são empoderantes, reforçam as relações de dependência ea percepção deimpotência do usuário frente ao poder público, econômico e social. As formas de relações baseadas no clientelismo, segundo Baque $\mathrm{rO}^{12}$, são assimiladas pela cultura e naturalizadas, "gerando no campo da política, uma cultura passiva, silenciosa e pouco participativa", permitindo que o assistencialismo vigore como mecanismo de controle dos cidadãos e manutenção política (ou da hierarquização social). Para o mesmo autor, esta situação se sustenta em virtude das deficiências do Estado em responder às demandas da população.

A fragilidade do reconhecimento das pessoas como cidadãos já foi revelada em outros estudos, como nas concepções de usuários de servi- ços de saúde sobre participação social ${ }^{13}$. M ais do que um desconhecimento dos seus direitos, segundo Gastal et al. ${ }^{14}$, a população apresenta uma sensação de resignação, de submissão. Estas conclusões são corroboradas ainda pelas observações de Santos citado por Marques ${ }^{3}$ de que os cidadãos de menores recursos tendem a conhecer pior os seus direitos e, portanto, a ter mais dificuldades em reconhecer um problema que os afeta como sendo problema jurídico.

Historicamente, os medicamentos são utilizados como moeda política, como demonstra Grimberg ${ }^{15}$ no caso argentino, sendo um dos temas tomados pelos movimentos sociais daquele país para a crítica ao modelo degestão do sistema público. Na experiência da autora, a saúde, como direito a ser exercido edemandado, éum dosmais importantes instrumentos de mobilização e coesão social. A partir de la salud, se denuncian y articulan temas políticos, sociales y de género, se mobilizan personas y se ejecutan distintas actividades, se disputan recursos y se convoca a variados sectores sociales. 0 fenômeno brasileiro de garantia do direito à saúde pela judicialização, no entanto, não apresenta indicativos concretos de queesteja contribuindo para a desejada mobilização da sociedade enquanto coletividade.

0 "empowerment comunitário" defendido por Carval ho ${ }^{16}$ não pode ser observado nos casos aqui relatados. Talvez o desenvolvimento do enfrentamento da aids no Brasil possa ser indicado como uma experiência em que o acesso a serviços e medicamentos está historicamente relacionado à mobilização da sociedade para a coletividade, sendo a mobilização social motivadora do acesso e vice-versa ${ }^{17}$.

Cabe ressaltar que, como alerta Carvalho ${ }^{16}$, embora o desenvolvimento crítico dos indivíduos não seja suficiente para a transformação da sociedade, ele é absolutamente necessário para que ela ocorra, uma vez que o envolvimento em processos demudança demanda um mínimo de percepção do poder individual que sustente um processo produtivo de convivência nos espaços coletivos. Diante dos resultados, aqui destacados, da falta deconscientização dos usuários a respeito da garantia de seu direito que está sendo declarada através dos processos judiciais, conclui-se que os avanços na garantia dos di reitos sociais conquistados não são, necessariamente, decorrentes da mobilização social coletiva - uma vez queéconfigurada como ações individuais - tampouco individual - por não estar representando um movimento consciente dos autores (na realidade, receptores) dos processos judiciais. 
Fica evidente a necessidade de que os serviços de saúde e demais atores sociais envolvidos no processo de acesso aos medicamentos tenham como objetivo final contribuir para a formação de cidadãos. Como sugere Carvalho ${ }^{16}$, os serviços de saúde no Brasil precisam ir além de prevenir, curar e reabilitar: devem contribuir para 0 aumento da capacidade reflexiva e de intervenção de diferentes sujeitos sobre o social, conscientes de seu direito e do "direito deter direitos". Apenas destamaneira entende-sequeserá possível compatibilizar a garantia dos direitos sociais com os princípios do uso racional demedicamentos, contando com os usuários e as organizações da sociedade civil como construtores da equidade, integralidade e universalidade e independentes de pressões comerciais ou corporativas sobreo uso abusi- vo detecnologias naárea da saúde eassim evitando que as estruturas do Estado tornem-se simples fontes de atendimento a interesses privados.

\section{Colaboradores}

SN Leite analisou os achados de campo e redigiu o texto e AC M afra coletou e colaborou na análise dos resultados.

\section{Agradecimentos}

À Probic, UNIVALI.

\section{Referências}

1. Brasil. Lei Orgânica da Saúde 8.080 de 19 setembro de 1990. Dispõe sobre as condições para a promoção, proteção e recuperação da saúde, a organização e o funcionamento dos serviços correspondentes e dá outras providências. Diário O ficial da U nião 1990; 20 set.

2. Lopes $C R$, Vasconcelos W. Quando o remédio vira veneno. Radis 2006; 43:10-13.

3. Marques SB. A garantia do direito social à assistência farmacêutica: o papel do sistema jurídico e do sistema político. Revista de Direito Sanitário 2006; 7(1/2/3):195-217.

4. Messeder NM, Castro CGSO, Luiza VL. Mandatos judiciais como ferramentas para garantia do acesso a medicamentos no setor público: a experiência do Estado do Rio de Janeiro. Cad Saude Publica 2005; 21(2):525-534.

5. Vieira FS, Zucchi P. Distorções causadas pelas ações judiciais à política de medicamentos no Brasil. Cad Saude Publica 2007; 41(1):101-107.

6. M arques SB, Dallari SG. Garantia do direito social à assistência farmacêutica no Estado de São Paulo. Cad Saude Publica 2005; 21(2):525-534.

7. Pereira J. Fornecimento de medicamentos por mandados judiciais contra o Estado deSanta Catarina 20042005 [dissertação]. Florianópolis (SC): Programa de Pós-graduação em Farmácia, Universidade Federal de Santa Catarina; 2006.

8. Victora CG, Hassen MNA, Knauth DR. Pesquisa qualitativa em saúde: uma introdução. Porto Alegre: Tomo Editorial; 2000.

9. M inayo M CS. Pesquisa social: teoria, método e criatividade. 11a ed. Petrópolis: Vozes; 1999.

10. Damatta R. 0 que faz o Brasil, Brasil? 11a ed. Rio de Janeiro: Rocco; 2000.

11. Damatta R. Carnavais, malandros e heróis - para uma sociologia do dilema brasileiro. 6 a ed. Rio de Janeiro: Rocco; 1997.
12. Baquero M. Construindo uma outra sociedade: 0 capital social na estruturação de uma cultura política participativa no Brasil. Revista de Sociologia política 2003; 21:83-108.

13. Vázquez ML, Silva MRF, Campos ES, Arruda IKG, Diniz AS, Veras IL, Pereira APC. Participação social nos serviços de saúde: concepções dos usuários e líderes comunitários em dois municípios do Nordeste do Brasil. Cad Saude Publica 2003; 19(2):579-591.

14. Gastal CLC, Gutfreind C. Um estudo comparativo de dois serviços de saúde mental: relações entre participação popular e representações sociais relacionadas ao direito à saúde. Cad Saude Publica 2007; 23(8):1835-1844.

15. Grimberg M. Protesta social y salud: un abordaje antropológico de las demandas e iniciativas de salud en el marco de la movilización social en la Argentina. In: M inayo M CS, Coimbra Jr CEA, organizadores. Críticas e aguantes - ciências sociais e humanas em saúde na America Latina. Rio de Janeiro: Fiocruz; 2005. p. 357-390.

16. Carvalho SR. Os múltiplos sentidos da categoria "empowerment" no projeto de Promoção à Saúde. Cad Saude Publica 2004; 20(4):1088-1095.

17. M arques MCC. Saúde e poder: a emergência política da Aids/HIV no Brasil. Hist. cienc. saude-M anguinhos 2002; 9:41-65.

Artigo apresentado em 03/09//2007

Aprovado em 14/12/2007 